\title{
J-shaped Relationship Between Chronic Kidney Disease and Serum Uric Acid Levels: A Cross-sectional Study on the Korean Population
}

\author{
Bon San Koo, M.D., Ph.D. ${ }^{1}$, , Hye-Jin Jeong, M.D. ${ }^{2}{ }^{*}$, Chang-Nam Son, M.D., Ph.D. ${ }^{2}$, \\ Sang-Hyon Kim, M.D., Ph.D. ${ }^{2}$, Gheun-Ho Kim, M.D., Ph.D. ${ }^{3}$, Jae-Bum Jun, M.D., Ph.D. ${ }^{4}$ \\ ${ }^{1}$ Department of Internal Medicine, Inje University Seoul Paik Hospital, Inje University College of Medicine, Seoul, ${ }^{2}$ Department of \\ Rheumatology, Keimyung University Dongsan Medical Center, Daegu, ${ }^{3}$ Department of Internal Medicine, Hanyang University College of \\ Medicine, ${ }^{4}$ Department of Rheumatology, Hanyang University Hospital for Rheumatic Diseases, Seoul, Korea
}

\begin{abstract}
Objective. Both hypouricemia and hyperuricemia are reportedly associated with reduced kidney function. This study investigated the association between uric acid levels and the risk of reduced renal function in men and women. Methods. We conducted a cross-sectional study using data from a government-funded health examinee cohort of a Korean genome and epidemiological study. A total of 172,970 participants (58,981 men, 113,989 women) aged 40 79 years were included. A logistic regression test was performed, and the odds ratio $(\mathrm{OR})$ and $95 \%$ confidence interval $(\mathrm{Cl})$ were calculated to examine the relationship between stratified uric acid levels and the frequency of chronic kidney disease. Results. As the uric acid level increased, the risk of reduced renal function increased. Moreover, for uric acid levels $\leq 2.0 \mathrm{mg} / \mathrm{dL}$, the risk of reduced renal function was higher than that of the reference group. Among the total, man, and woman groups, a statistically significant association was observed in men $(\mathrm{OR} 1.71,95 \% \mathrm{Cl} 0.945 \sim 3.111$, OR 5.003, 95\% Cl 1.405 17.809, and OR 1.377, 95\% Cl 0.696 2.724, respectively). Conclusion. The OR of reduced renal function according to uric acid levels formed a J-shaped curve in both genders. (J Rheum Dis 2021;28:225-233)
\end{abstract}

Key Words. Chronic kidney diseases, Hyperuricemia, Uric acid

\section{INTRODUCTION}

Abnormalities in uric acid levels are correlated with a variety of diseases. Hyperuricemia is an important risk factor for various systemic diseases including gout, hypertension, type 2 diabetes, chronic kidney disease, and cardiovascular diseases [1]. Since hyperuricemia is frequently found, it has been demonstrated to be associated with a variety of diseases based on the epidemiologic characteristics of different ethnic groups [2,3]. However, studies on the association of hypouricemia with other conditions are still scarce, compared to the volume of literature available on hyperuricemia.
Since $70 \%$ of uric acid is excreted by the kidneys, kidney function and uric acid levels are closely related [4]. Renal glomerular filtration, proximal tubular reabsorption, secretion, and post-secretory reabsorption are associated with the regulation of uric acid in the body [5]. Although it remains questionable whether uric acid is the cause of kidney disease, several studies have suggested that hyperuricemia may be a pathogenic factor in the development of chronic kidney disease [6]. However, there have recently been several reports revealing the association of hypouricemia with chronic kidney disease as well [7-9]. Although the pathophysiological mechanism is unclear, the role of both hypouricemia and hyperuricemia in de-

Received : April 23, 2021, Revised : June 5, 2021, Accepted : June 8, 2021

Corresponding to : Jae-Bum Jun (Dhttp://orcid.org/0000-0002-0208-0505

Department of Rheumatology, Hanyang University Hospital for Rheumatic Diseases, 222-1 Wangsimni-ro, Seongdong-gu, Seoul 04763, Korea. E-mail : junjb@hanyang.ac.kr

*These authors have contributed equally.

Copyright (c) 2021 by The Korean College of Rheumatology.

This is an Open Access article, which permits unrestricted non-commerical use, distribution, and reproduction in any medium, provided the original work is properly cited. 
termining renal function deserves closer examination. Therefore, it is necessary to stratify the risk of reduced renal function according to uric acid levels. Moreover, since uric acid distribution or the prevalence of uric acid-related disorders differ between men and women, it is necessary to evaluate the risk separately for men and women. A population-based study conducted in Japan confirmed a significant correlation between hypouricemia and reduced renal function in men [10]. Recently, the correlation between renal function and serum uric acid level has been revealed using single center data in Korea; however, it remains necessary to establish the correlation between them in large population groups [11]. Therefore, the aim of the study was to determine the association between the reduced renal function and the uric acid level in men and women using data from the population-based cohort in Korea.

\section{MATERIALS AND METHODS}

\section{Study population}

This cross-sectional study used baseline data from the health examinee (HEXA) cohort from the Korean genome and epidemiology study (KoGES), which was collected between 2004 and 2013 [12]. A total of 173,357 participants aged 40 79 years were included in this cohort. Among these, we excluded individuals with missing data on age, gender, serum uric acid, and serum creatinine levels. Participants being treated for gout were also excluded. In a previous study, we used this data to determine the prevalence of hyperuricemia and hypouricemia [13]. The study population was the same as that included in the previous study; the study design was, however, modified to assess the risk of reduced renal function according to uric acid levels [13]. This study was approved by the Institutional Review Board (HYUH2016-01-024) and performed in accordance with the guidelines laid down by the Declaration of Helsinki (1964) and its later amendments. Informed consent was waived by the board because of the retrospective nature of the study.

\section{Data collection}

Information on the medical history, use of medications, alcohol consumption, smoking, exercise, and family history was collected from the questionnaires. History of underlying cardiovascular conditions such as angina and myocardial infarction, and cerebrovascular conditions such as stroke (except transient ischemic attack) was also collected. Physical examination including blood pressure, height, weight, and waist circumference was performed during the health screening. Body mass index (BMI) was calculated as weight (in $\mathrm{kg}$ ) divided by the square of height (in $\mathrm{m}$ ). Serum uric acid levels were categorized as $\leq 2$, $2.1 \sim 3.0,3.1 \sim 4.0,4.1 \sim 5.0,5.1 \sim 6.0,6.1 \sim 7.0$, and $>7 \mathrm{mg} / \mathrm{dL}$, with the median category $(4.1 \sim 5.0 \mathrm{mg} / \mathrm{dL})$ set as the reference category. In addition, participants were categorized as quartiles of serum uric acid levels (5th, 20th, 80th, and 95th percentiles) in men and women. Hypouricemia was defined as serum uric acid levels $\leq 2 \mathrm{mg} / \mathrm{dL}$, and hyperuricemia was defined as serum uric acid levels $>7 \mathrm{mg} / \mathrm{dL}$. The estimated glomerular filtration rate (eGFR) was obtained by the Modification of Diet in Renal Disease (MDRD) study equation: eGFR $\left(\mathrm{mL} / \mathrm{min}\right.$ per $\left.1.73 \mathrm{~m}^{2}\right)=186 \times(\text { serum creatinine })^{-1.154}$ $\times(\text { age })^{-0.203} \times 1.212$ (if Black) $\times 0.742$ (if female) $[14,15]$. The main outcome was reduced renal function, defined as eGFR $<60 \mathrm{~mL} / \mathrm{min} / 1.73 \mathrm{~m}^{2}$. Proteinuria and glycosuria were defined as $1+$ or greater result (equivalent to $\geq 30$ $\mathrm{mg} / \mathrm{dL}$ ) on a dipstick urinalysis.

\section{Statistical analysis}

Data were analyzed separately by sex, because the serum uric acid levels differ depending on gender. All values are presented as mean \pm standard deviation, number (\%), or median (interquartile range). Comparison of clinical characteristics by serum uric acid levels was performed using the analysis of variance or the t-test for continuous data, and the chi-square test for categorical data. Logistic regression analysis was used to test the association between hypouricemia and reduced renal function after adjusting for potential confounding variables such as age, gender, drinking status, smoking status, exercise, medical history, BMI, blood urea nitrogen, proteinuria, glycosuria, and serum uric acid levels. All data were analyzed using IBM SPSS statistical software version 23 for Windows (IBM Corp., Armonk, NY, USA) and p-values less than 0.05 were considered statistically significant.

\section{RESULTS}

\section{Clinical characteristics}

Patient enrolment has been described in a previous study [13]. The clinical characteristics of the participants are shown in Table 1 . The average age was 53.1 \pm 8.4 ; $45.2 \%$ were current drinkers and $12.4 \%$ were current 
Table 1. Baseline characteristics of total participants $(n=172,970)$

\begin{tabular}{|c|c|c|c|c|}
\hline Variable & $\begin{array}{c}\text { Total } \\
(\mathrm{n}=172,970)\end{array}$ & $\begin{array}{c}\text { Men } \\
(n=58,981)\end{array}$ & $\begin{array}{c}\text { Women } \\
(\mathrm{n}=113,989)\end{array}$ & p-value \\
\hline Age (yr) & $53.1 \pm 8.4$ & $54.0 \pm 8.8$ & $52.6 \pm 8.1$ & $<0.001$ \\
\hline \multicolumn{5}{|l|}{ Drinking status } \\
\hline Never & $87,166(50.8)$ & $11,870(20.3)$ & $75,296(66.7)$ & \multirow[t]{3}{*}{$<0.001$} \\
\hline Former & $6869(4.0)$ & $4,387(7.5)$ & $2,482(2.2)$ & \\
\hline Current & $77,509(45.2)$ & $42,346(72.3)$ & $35,163(31.1)$ & \\
\hline \multicolumn{5}{|l|}{ Smoking status } \\
\hline Never & $125,022(72.9)$ & $16,380(28.0)$ & $108,642(96.3)$ & \multirow[t]{3}{*}{$<0.001$} \\
\hline Former & $25,084(14.6)$ & $23,594(40.3)$ & $1,490(1.3)$ & \\
\hline Current & $21,277(12.4)$ & $18,608(31.8)$ & $2,669(2.4)$ & \\
\hline Exercise & $90,173(52.5)$ & $33,080(56.5)$ & $57,093(50.5)$ & $<0.001$ \\
\hline \multicolumn{5}{|l|}{ Medical history } \\
\hline Hypertension & $33,384(19.4)$ & $13,193(22.5)$ & $20,191(17.8)$ & $<0.001$ \\
\hline Diabetes & $11,479(6.7)$ & $5,464(9.3)$ & $6,015(5.3)$ & $<0.001$ \\
\hline Cardiovascular disease & $4,298(2.5)$ & $2,108(3.6)$ & $2,190(1.9)$ & $<0.001$ \\
\hline Cerebrovascular disease & $2,102(1.2)$ & $11,479(6.7)$ & $1,053(0.9)$ & $<0.001$ \\
\hline Malignancy & $5,256(3.1)$ & $1,305(2.2)$ & $3,951(3.5)$ & $<0.001$ \\
\hline Chronic kidney disease & $3,766(2.2)$ & $1,538(2.6)$ & $2,228(2.0)$ & $<0.001$ \\
\hline \multicolumn{5}{|l|}{ Physical findings } \\
\hline Systolic BP (mmHg) & $122.7 \pm 15.5$ & $125.9 \pm 14.7$ & $121.1 \pm 15.6$ & $<0.001$ \\
\hline Diastolic BP (mmHg) & $76.2 \pm 10.0$ & $78.7 \pm 9.9$ & $74.9 \pm 9.9$ & $<0.001$ \\
\hline Body mass index $\left(\mathrm{kg} / \mathrm{m}^{2}\right)$ & $23.9 \pm 2.9$ & $24.4 \pm 2.7$ & $23.7 \pm 3.0$ & $<0.001$ \\
\hline Waist circumference (cm) & $81.1 \pm 8.7$ & $85.8 \pm 7.5$ & $78.6 \pm 8.2$ & $<0.001$ \\
\hline \multicolumn{5}{|l|}{ Laboratory results } \\
\hline Fasting serum glucose (mg/dL) & $95.2 \pm 21.6$ & $99.2 \pm 24.5$ & $93.1 \pm 19.6$ & $<0.001$ \\
\hline Total cholesterol $(\mathrm{mg} / \mathrm{dL})$ & $197.5 \pm 35.6$ & $193.3 \pm 34.9$ & $199.6 \pm 35.8$ & $<0.001$ \\
\hline HDL cholesterol (mg/dL) & $54.0 \pm 12.9$ & $49.7 \pm 12.0$ & $56.3 \pm 12.9$ & $<0.001$ \\
\hline Triglyceride (mg/dL) & $126.8 \pm 89.7$ & $151.1 \pm 108.7$ & $114.2 \pm 74.9$ & $<0.001$ \\
\hline $\mathrm{B} \cup N(\mathrm{mg} / \mathrm{dL})$ & $14.3 \pm 4.0$ & $15.1 \pm 4.1$ & $13.9 \pm 3.9$ & $<0.001$ \\
\hline Creatinine (mg/dL) & $0.8 \pm 0.2$ & $1.0 \pm 0.2$ & $0.7 \pm 0.2$ & $<0.001$ \\
\hline eGFR $\left(\mathrm{mL} / \mathrm{min} / 1.73 \mathrm{~m}^{2}\right)$ & $89.5 \pm 16.5$ & $87.9 \pm 15.6$ & $90.3 \pm 16.8$ & $<0.001$ \\
\hline Total bilirubin (mg/dL) & $0.7 \pm 0.3$ & $0.8 \pm 0.3$ & $0.7 \pm 0.3$ & $<0.001$ \\
\hline r-GT (IU/L) & $31.2 \pm 45.2$ & $48.4 \pm 66.6$ & $22.2 \pm 23.9$ & $<0.001$ \\
\hline AST (IU/L) & $23.9 \pm 18.0$ & $26.1 \pm 16.1$ & $22.8 \pm 18.8$ & $<0.001$ \\
\hline ALT (IU/L) & $22.5 \pm 21.8$ & $27.2 \pm 21.4$ & $20.0 \pm 21.7$ & $<0.001$ \\
\hline Proteinuria & $4,202(2.6)$ & $1,717(3.1)$ & $2,485(2.4)$ & $<0.001$ \\
\hline Glycosuria & $1,826(1.1)$ & $1,083(2.0)$ & $743(0.7)$ & $<0.001$ \\
\hline \multicolumn{5}{|l|}{ Uric acid levels (mg/dL) } \\
\hline$\leq 2.0$ & $720(0.4)$ & $65(0.1)$ & $655(0.6)$ & \multirow[t]{7}{*}{$<0.001$} \\
\hline $2.1 \sim 3.0$ & $10,874(0.4)$ & $758(1.3)$ & $10,116(8.9)$ & \\
\hline $3.1 \sim 4.0$ & $46,049(26.6)$ & $4,125(7.0)$ & $41,924(36.8)$ & \\
\hline $4.1 \sim 5.0$ & $55,115(31.9)$ & $12,970(22.0)$ & $42,145(37.0)$ & \\
\hline $5.1 \sim 6.0$ & $34,545(20.0)$ & $19,532(33.1)$ & $15,013(13.2)$ & \\
\hline $6.1 \sim 7.0$ & $16,877(9.8)$ & $13,672(23.2)$ & $3,205(2.8)$ & \\
\hline$>7.0$ & $8,790(5.1)$ & $7,859(13.3)$ & $931(0.8)$ & \\
\hline
\end{tabular}

Values are presented as mean \pm standard deviation, number (\%). Patients with missing values were not included. BP: blood pressure, BUN: blood urea nitrogen, HDL: high density lipoprotein, eGFR: estimated glomerular filtration rate, r-GT: gamma-glutamyl transferase, AST: aspartate transaminase, ALT: alanine transaminase.

smokers. As for the medical history, $2.2 \%$ of participants had chronic kidney disease. Most participants had uric acid levels in the range of $4.1 \sim 5.1 \mathrm{mg} / \mathrm{dL}$. Among varia- bles, a statistically significant difference between men and women could be seen with respect to smoking and drinking status, medical history, and uric acid levels. 


\section{Relationship between serum uric acid level and reduced renal function}

A scatter plot shows the relationship between serum uric acid level and MDRD eGFR (Figure 1). There were more male participants with higher serum uric acid levels than female. When comparing the regression lines, eGFR in hypouricemia was similar in men and women; however, as the serum uric acid level increased, the eGFR decreased more in women than in men.

The prevalence of reduced renal function participants

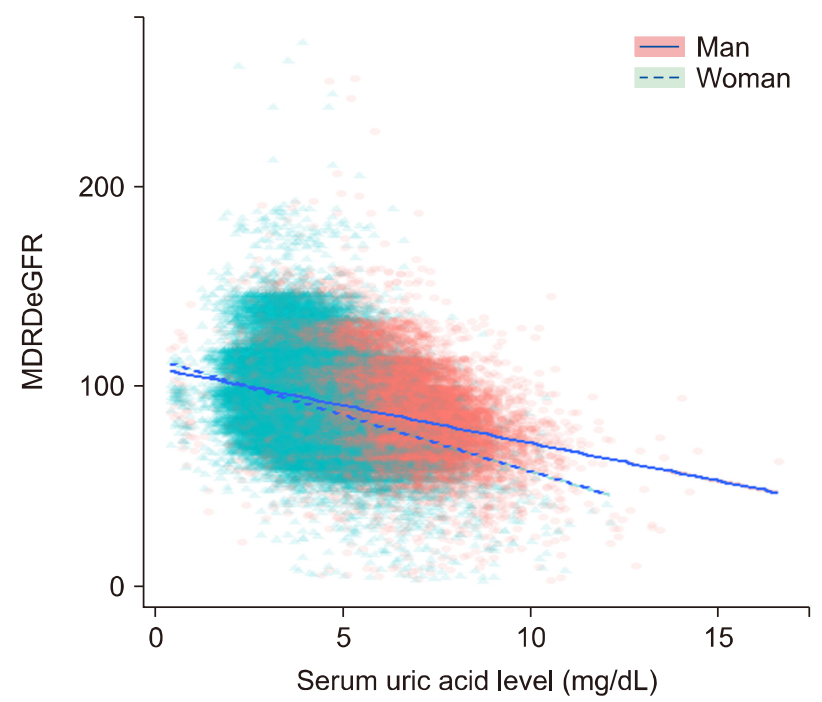

Figure 1. Relationship between serum uric acid levels and eGFR. MDRD: Modification of Diet in Renal Disease, eGFR: estimated glomerular filtration rate. was calculated according to the serum uric acid level category (Figure 2). The prevalence of reduced renal function was higher in men than in women with hypouricemia. However, in those with hyperuricemia, the prevalence of reduced renal function was higher in women than in men. Regarding the classification by quartiles of the serum uric acid, the 5th, 20th, 80th, and 95th percentiles were 3.7, 4.7, 6.7, and $7.9 \mathrm{mg} / \mathrm{dL}$ in men and 2.8, 3.4, 4.9, and 5.9 $\mathrm{mg} / \mathrm{dL}$ in women, respectively. Figure 3 shows the prevalence of chronic kidney disease in five quartiles in men and women. The prevalence of Q1 with the lowest serum uric acid level (serum uric acid level $<3.7 \mathrm{mg} / \mathrm{dL}$ in men and $<2.8 \mathrm{mg} / \mathrm{dL}$ in women) was higher in men than in women and the prevalence of Q5 with the highest serum uric acid level (serum uric acid level $\geq 7.9 \mathrm{mg} / \mathrm{dL}$ in men and $\geq 5.9 \mathrm{mg} / \mathrm{dL}$ in women) was higher in women than in men.

\section{The association between uric acid levels and reduced renal function in the total group}

To examine the relationship between each variable and the renal function, the unadjusted odds ratio (OR) was evaluated in the total, man, and woman participant groups (Supplementary Table 1). Among these, the statistically significant variables were included in the analysis of the adjusted OR (Table 2). In the total group, age and gender were significantly associated with reduced renal function (OR 1.097, 95\% confidence interval (CI) 1.091 1.103 and OR 2.491, 95\% CI 2.201 2.818, respectively).

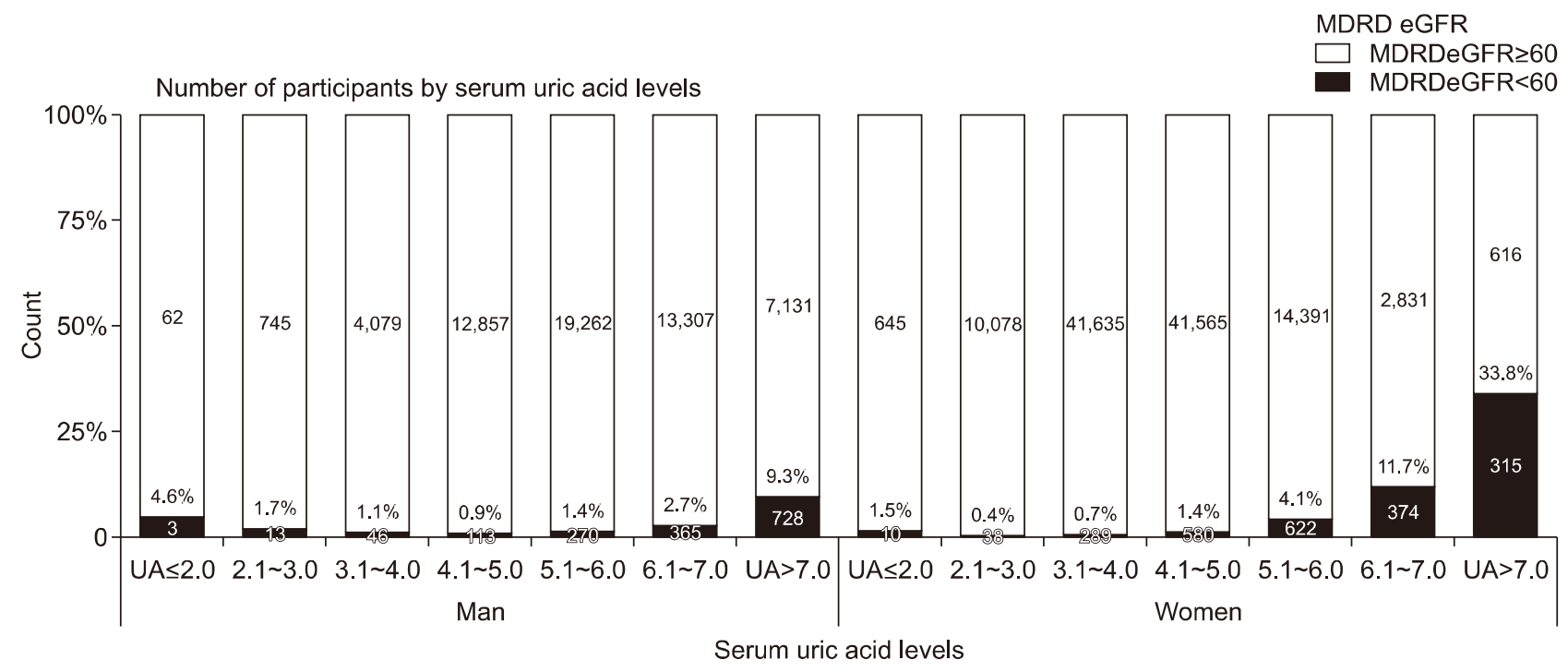

Figure 2. Prevalence of reduced renal function according to serum uric acid levels. MDRD: Modification of Diet in Renal Disease, eGFR: estimated glomerular filtration rate, UA: uric acid level. 


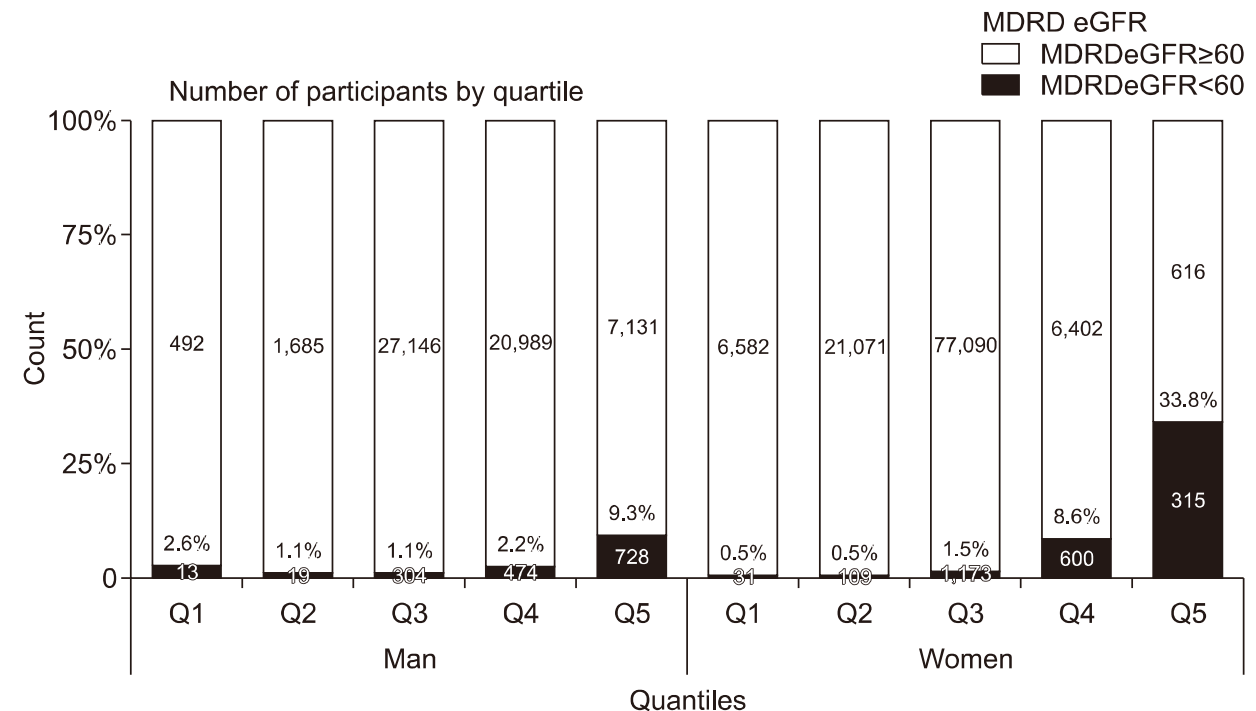

Figure 3. Prevalence of reduced renal function according to percentiles of serum uric acid levels (5th, 20th, 80th, and 95th). MDRD: Modification of Diet in Renal Disease, eGFR: estimated glomerular filtration rate, Q1: first quartile, Q2: second quartile, Q3: third quartile, Q4: fourth quartile, Q5: fifth quartile.

Table 2. Adjusted odds ratio for the association between serum uric acid and reduced renal function in total, men, and women participants

\begin{tabular}{|c|c|c|c|c|c|c|}
\hline \multirow{2}{*}{ Variable } & \multicolumn{2}{|l|}{ Total } & \multicolumn{2}{|l|}{ Men } & \multicolumn{2}{|l|}{ Women } \\
\hline & OR $(95 \% \mathrm{Cl})$ & p-value & OR $(95 \% \mathrm{Cl})$ & p-value & OR $(95 \% \mathrm{Cl})$ & p-value \\
\hline Age (yr) & 1.097 (1.091 1.103) & $<0.001$ & $1.087(1.078 \sim 1.096)$ & $<0.001$ & 1.107 (1.099 1.116) & $<0.001$ \\
\hline Women & 2.491 (2.201 2.818) & $<0.001$ & & & & \\
\hline \multicolumn{7}{|l|}{ Drinking status } \\
\hline Never & Reference & & Reference & & Reference & \\
\hline Former & 0.977 (0.821 1.161) & 0.790 & 0.906 (0.733 1.120) & 0.362 & 0.868 (0.609 1.235) & 0.431 \\
\hline Current & $0.732(0.665 \sim 0.806)$ & $<0.001$ & $0.639(0.554 \sim 0.736)$ & $<0.001$ & $0.828(0.728 \sim 0.941)$ & 0.004 \\
\hline \multicolumn{7}{|l|}{ Smoking status } \\
\hline Never & Reference & & Reference & & Reference & \\
\hline Former & 0.994 (0.873 1.133) & 0.930 & 0.980 (0.852 1.128) & 0.783 & $1.373(0.923 \sim 2.041)$ & 0.117 \\
\hline Current & $0.922(0.790 \sim 1.075)$ & 0.299 & 0.953 (0.801 1.134) & 0.588 & $0.853(0.589 \sim 1.236)$ & 0.401 \\
\hline Exercise & 1.013 (0.937 1.094) & 0.752 & 1.063 (0.939 1.204) & 0.334 & 0.979 (0.887 1.081) & 0.674 \\
\hline \multicolumn{7}{|l|}{ Medical history } \\
\hline Hypertension & 1.448 (1.333 1.572) & $<0.001$ & $1.632(1.436 \sim 1.853)$ & $<0.001$ & $1.311(1.176 \sim 1.461)$ & $<0.001$ \\
\hline Diabetes & $1.604(1.442 \sim 1.784)$ & $<0.001$ & $1.630(1.389 \sim 1.913)$ & $<0.001$ & $1.571(1.361 \sim 1.813)$ & $<0.001$ \\
\hline Cardiovascular disease & 1.667 (1.444 1.923) & $<0.001$ & $1.703(1.392 \sim 2.084)$ & $<0.001$ & $1.615(1.316 \sim 1.981)$ & $<0.001$ \\
\hline Cerebrovascular disease & $1.828(1.495 \sim 2.236)$ & $<0.001$ & $1.840(1.388 \sim 2.439)$ & $<0.001$ & $1.803(1.352 \sim 2.404)$ & $<0.001$ \\
\hline Malignancy & $1.136(0.939 \sim 1.375)$ & 0.189 & $1.622(1.209 \sim 2.177)$ & 0.001 & $0.918(0.711 \sim 1.185)$ & 0.511 \\
\hline Body mass index $\left(\mathrm{kg} / \mathrm{m}^{2}\right)$ & 0.994 (0.981 1.007) & 0.372 & $1.033(1.009 \sim 1.056)$ & 0.006 & $0.970(0.954 \sim 0.987)$ & $<0.001$ \\
\hline BUN (mg/dL) & $1.200(1.191 \sim 1.210)$ & $<0.001$ & $1.210(1.194 \sim 1.225)$ & $<0.001$ & $1.192(1.180 \sim 1.205)$ & $<0.001$ \\
\hline Proteinuria & 2.725 (2.368 3.135) & $<0.001$ & $2.838(2.320 \sim 3.471)$ & $<0.001$ & $2.578(2.119 \sim 3.137)$ & $<0.001$ \\
\hline Glycosuria & $1.534(1.196 \sim 1.967)$ & 0.001 & $1.291(0.923 \sim 1.807)$ & 0.136 & 1.808 (1.249 2.618) & 0.002 \\
\hline \multicolumn{7}{|l|}{ Uric acid category (mg/dL) } \\
\hline$\leq 2.0$ & $1.715(0.945 \sim 3.111)$ & 0.076 & $5.003(1.405 \sim 17.809)$ & 0.013 & 1.377 (0.696 2.724) & 0.358 \\
\hline $2.1 \sim 3.0$ & $0.426(0.315 \sim 0.576)$ & $<0.001$ & $1.444(0.766 \sim 2.721)$ & 0.256 & $0.336(0.238 \sim 0.475)$ & $<0.001$ \\
\hline $3.1 \sim 4.0$ & $0.674(0.585 \sim 0.777)$ & $<0.001$ & $1.061(0.727 \sim 1.547)$ & 0.760 & $0.632(0.542 \sim 0.737)$ & $<0.001$ \\
\hline $4.1 \sim 5.0$ & Reference & & Reference & & Reference & \\
\hline $5.1 \sim 6.0$ & 2.070 (1.848 2.318) & $<0.001$ & $1.693(1.328 \sim 2.160)$ & $<0.001$ & $2.252(1.980 \sim 2.562)$ & $<0.001$ \\
\hline $6.1 \sim 7.0$ & $4.132(3.638 \sim 4.692)$ & $<0.001$ & $3.240(2.556 \sim 4.106)$ & $<0.001$ & 5.030 (4.287 5.901) & $<0.001$ \\
\hline$>7.0$ & $11.884(10.395 \sim 13.588)$ & $<0.001$ & $10.417(8.287 \sim 13.094)$ & $<0.001$ & $11.821(9.608 \sim 14.543$ & $<0.001$ \\
\hline
\end{tabular}

OR: odds ratio, $\mathrm{Cl}$ : confidence interval, BP: blood pressure, BUN: blood urea nitrogen, HDL: high density lipoprotein, eGFR: estimated glomerular filtration rate, r-GT: gamma-glutamyl transferase, AST: aspartate transaminase, ALT: alanine transaminase. 
Current drinkers were associated with a lower risk of reduced renal function than teetotalers (OR 0.732, 95\% CI $0.665 \sim 0.806)$. Hypertension, diabetes, cardiovascular disease, and cerebrovascular disease were significantly associated with reduced renal function (OR 1.448, 95\% CI 1.333 1.572; OR 1.604, 95\% CI 1.442 1.784; OR 1.667, 95\% CI 1.444 1.923; and OR 1.828, 95\% CI $1.495 \sim 2.236$, respectively).

Among all participants, there was no significant difference between the uric acid $\leq 2.0 \mathrm{mg} / \mathrm{dL}$ group and the reference group (OR 1.715, 95\% CI 0.945 3.111). However, the $2.1 \sim 3.0 \mathrm{mg} / \mathrm{dL}$ and $3.1 \sim 4.0 \mathrm{mg} / \mathrm{dL}$ groups had significantly lower OR (OR 0.426, 95\% CI $0.315 \sim 0.576$ and OR $0.674,95 \%$ CI $0.585 \sim 0.777$, respectively), and the $5.1 \sim 6.0 \mathrm{mg} / \mathrm{dL}, 6.1 \sim 7.0 \mathrm{mg} / \mathrm{dL}$, and $>7.0 \mathrm{mg} / \mathrm{dL}$ groups had significantly higher OR than that of the reference group (OR 2.070, 95\% CI 1.848 2.318; OR 4.132, 95\% CI 3.638 4.692; and OR 11.884, $95 \%$ CI 10.395 13.588, respectively). The graphical representation of the OR according to the uric acid category formed a J-shaped curve (Figure 4).

\section{The association between uric acid levels and reduced renal function in men and women}

Variables related to reduced renal function in men and women were similar to those of the total participants group (Table 2). However, malignancy increased the risk of reduced renal function in men (OR 1.622, 95\% CI $1.209 \sim 2.177$ ), but not in women (OR 0.918, 95\% CI $0.711 \sim 1.185)$. In addition, glycosuria increased the risk

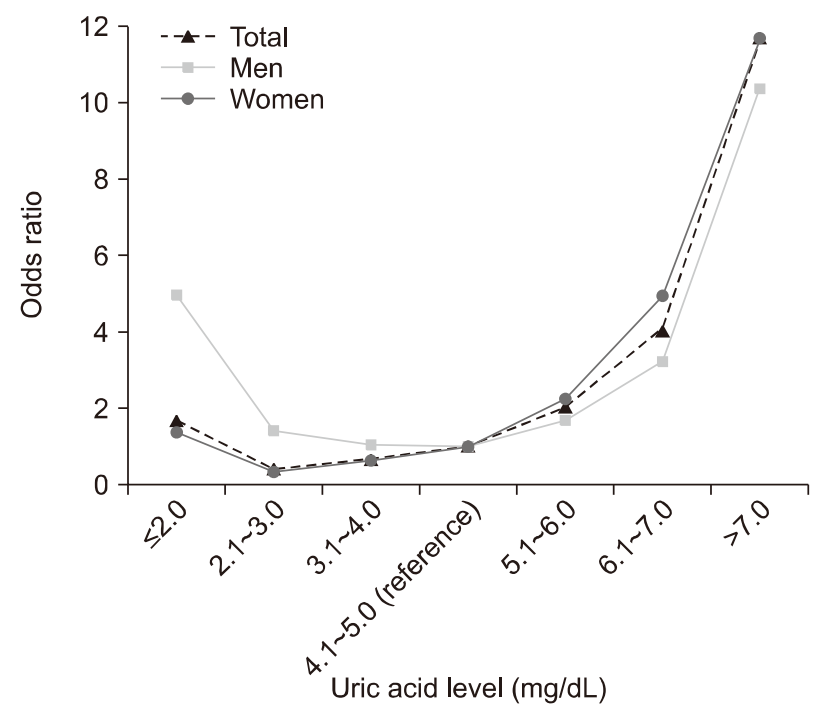

Figure 4. The odd ratio of reduced renal function in total, men, and women participants according to uric acid level. of reduced renal function in women (OR 1.808, 95\% CI $1.249 \sim 2.618$ ), but not in men (OR 1.291, 95\% CI 0.923 1.807).

The group with uric acid $\leq 2.0 \mathrm{mg} / \mathrm{dL}$ had a significantly higher risk of reduced renal function than the reference group in men (OR 5.003, 95\% CI $1.405 \sim 17.809$ ), though not in women (OR 1.377, 95\% CI 0.696 2.724). Meanwhile, groups with uric acid levels $2.1 \sim 3.0 \mathrm{mg} / \mathrm{dL}$ and $3.1 \sim 4.0 \mathrm{mg} / \mathrm{dL}$ had a significantly lower risk of reduced renal function than the reference group in women (OR 0.336, 95\% CI 0.238 0.475 and OR 0.632 95\% CI $0.542 \sim 0.737$, respectively), though not in men (OR $1.444,95 \%$ CI $0.766 \sim 2.721$ and OR 1.061, 95\% CI 0.727 $\sim 1.547$, respectively). The graphical representation of the OR according to the uric acid category in men and women was also found to be J-shaped, similar to that of the total participants (Figure 4).

\section{DISCUSSION}

We investigated the relationship between serum uric acid levels and reduced renal function in a nationwide population cohort of Korea and found a J-shaped distribution of the OR of reduced renal function according to uric acid levels. Notably, the hypouricemia group showed a significantly higher OR of reduced renal function than the normal uric acid group in men (OR 5.003, 95\% CI $0.766 \sim 2.721$ ).

It is known that hyperuricemia is a risk factor for renal impairment due to reduced GFR [16-20]. Hyperuricemia reduces the function of renal vascular endothelial cells by decreasing nitric oxide synthesis and increasing the resistance of the renal arteries [21,22]. Recently, a few studies have reported that hypouricemia is also associated with decreased renal function $[10,23]$. This suggests that the risk of reduced renal function appears to be J-shaped or U-shaped, which increases not only in hyperuricemia but also in hypouricemia [7,11,24,25].

Various studies suggested that hypouricemia and kidney function are closely related. Hypouricemia is associated with exercise-induced acute kidney injury and nephrolithiasis [26-31]. Recently, uric acid metabolism in the kidney was further elucidated by the identification of uric acid transporters such as the human urate transporter 1 and human glucose transporter-like protein 9 (GLUT-9) in the renal tubules [23]. In addition, it was suggested that glomerular hyperfiltration in diabetes mellitus lowers the serum uric acid levels by increasing the renal clear- 
ance of urate [32].

Additionally, we identified subtle differences in serum uric acid and reduced renal function between men and women. It has been previously suggested that hormones, among various factors, are related to differences in uric acid levels between men and women $[10,33]$. The relationship between menopause and serum uric acid is evidence of a hormonal contribution [10,34]. In participants with hypouricemia, an increase in the OR of reduced renal function in women than in men may be hormonally related. Multidisciplinary laboratory studies on uric acid and renal function are needed in the future.

The link between hypouricemia and chronic kidney disease has become clearer from epidemiological studies. Compared with the serum uric acid level of $2.0 \sim 4.5$ $\mathrm{mg} / \mathrm{dL}$ in a large population undergoing a health check-up in Taiwan, the multivariate-adjusted hazard ratio for chronic kidney disease and hypouricemia $(<2.0$ $\mathrm{mg} / \mathrm{dL})$ was 1.65 (95\% CI 0.53 5.15) [8]. In a population-based cross-sectional study on 90,710 participants from Japan, hypouricemia was associated with reduced kidney function (eGFR $<60 \mathrm{~mL} / \mathrm{min} / 1.73 \mathrm{~m}^{2}$ ) in men (OR 1.83, 95\% CI 1.23 2.74) but not in women (OR 0.61, 0.43 0.86), relative to the reference level of serum uric acid (4.1 $\sim 5.0 \mathrm{mg} / \mathrm{dL})$ [10]. In our study, the risk in the $\leq 2.0 \mathrm{mg} / \mathrm{dL}$ group was significantly higher than the reference level $(4.1 \sim 5.0 \mathrm{mg} / \mathrm{dL}$ ) in men (OR 5.003). Aside from the differences in the study design, the risk of hypouricemia may have been higher than that of the normal uric acid group in our study because all the participants were aged 40 years or older. In a recent single center study on 143,762 adults who underwent health screening in Korea, low serum uric acid levels $(<5.0$ $\mathrm{mg} / \mathrm{dL}$ ) was significantly associated with end-stage renal disease in men compared to the reference uric acid level $(5.80 \sim 6.39 \mathrm{mg} / \mathrm{dL})($ hazard ratio=1.90) [11]. However, our study defined the lowest level of uric acid as $<2.0$ $\mathrm{mg} / \mathrm{dL}$ in both men and women, whereas the aforementioned study defined the lowest level of uric acid as $<5.0 \mathrm{mg} / \mathrm{dL}$ and $<3.6 \mathrm{mg} / \mathrm{dL}$ in men and women, respectively. Our study presented the specific range of uric acid levels associated with the risk of reduced renal function stratified by gender and provided strong evidence for an epidemiological link between hypouricemia and reduced kidney function using a large population-based cohort. However, in order to lower the risk of chronic kidney disease, further research to confirm the causal relationship between uric acid and reduced renal function is essential.

We found several factors related to reduced renal function. Current drinking status might be related to a lower risk of reduced renal function regardless of gender. Other studies have also suggested an inverse relationship between alcohol consumption and the risk of reduced renal function [35,36]. In addition, an inverse association between alcohol intake and annual eGFR decline and incident low eGFR was observed in the analysis of Korean health screening data of 14,190,878 participants [37]. We found that medical history showed a significant association with the reduced occurrence of renal disease. However, malignancy was related to reduced renal function only in men. BMI was related to an increase in the risk of reduced renal function in men, and in contrast, a decrease in the risk of reduced renal function in women. Further research is needed to elucidate the various relationships between renal function and gender-related comorbidities.

The present study has several limitations. First, given the cross-sectional study design, we could not assess factors leading to the incidence of renal insufficiency, according to uric acid levels. Second, there was a selection bias due to the inclusion of subjects of a certain age group who had health-screening data and lived in urban areas. Finally, the homogeneity of data may have deteriorated because the data was collected at baseline for long periods.

\section{CONCLUSION}

In conclusion, the odd ratio of reduced renal function according to uric acid levels formed a J-shaped curve in a large population-based cohort of Korea. The risk of reduced renal function was significantly higher in hypouricemia than in normal uric acid levels among men, not women. Therefore, it is necessary to consider the association with kidney disease in men with hypouricemia.

\section{ACKNOWLEDGMENTS}

This study was conducted with bioresources from the National Biobank of Korea, the Centers for Disease Control and Prevention, Republic of Korea (KBP-2016011).

\section{CONFLICT OF INTEREST}

No potential conflict of interest relevant to this article 
was reported.

\section{AUTHOR CONTRIBUTIONS}

Conceptualization: B.S.K., H.J.J., and J.B.J. Data acquisition: H.J.J. and J.B.J. Formal analysis: B.S.K., H.J.J., and J.B.J. Funding: J.B.J. Supervision: C.N.S., S.H.K., G.H.K., and J.B.J. Writing-original draft: B.S.K and H.J.J. Writing -review \& editing: All authors.

\section{SUPPLEMENTARY DATA}

Supplementary data can be found with this article online at https://doi.org/10.4078/jrd.2021.28.4.225.

\section{REFERENCES}

1. Rock KL, Kataoka H, Lai JJ. Uric acid as a danger signal in gout and its comorbidities. Nat Rev Rheumatol 2013;9: 13-23.

2. Singh JA. Racial and gender disparities among patients with gout. Curr Rheumatol Rep 2013;15:307.

3. Singh JA, Gaffo A. Gout epidemiology and comorbidities. Semin Arthritis Rheum 2020;50(3S):S11-6.

4. Maesaka JK, Fishbane S. Regulation of renal urate excretion: a critical review. Am J Kidney Dis 1998;32:917-33.

5. Roch-Ramel F, Guisan B. Renal transport of urate in humans. News Physiol Sci 1999;14:80-4.

6. Sharaf El Din UAA, Salem MM, Abdulazim DO. Uric acid in the pathogenesis of metabolic, renal, and cardiovascular diseases: a review. J Adv Res 2017;8:537-48.

7. Kanda E, Muneyuki T, Kanno Y, Suwa K, Nakajima K. Uric acid level has a U-shaped association with loss of kidney function in healthy people: a prospective cohort study. PLoS One 2015;10:e0118031.

8. Wang S, Shu Z, Tao Q, Yu C, Zhan S, Li L. Uric acid and incident chronic kidney disease in a large health check-up population in Taiwan. Nephrology (Carlton) 2011;16: 767-76.

9. Park JH, Jo YI, Lee JH. Renal effects of uric acid: hyperuricemia and hypouricemia. Korean J Intern Med 2020;35: 1291-304.

10. Wakasugi M, Kazama JJ, Narita I, Konta T, Fujimoto S, Iseki $\mathrm{K}$, et al. Association between hypouricemia and reduced kidney function: a cross-sectional population-based study in Japan. Am J Nephrol 2015;41:138-46.

11. Kim K, Go S, Son HE, Ryu JY, Lee H, Heo NJ, et al. Association between serum uric acid level and ESRD or death in a Korean population. J Korean Med Sci 2020; 35:e254.

12. Kim Y, Han BG; KoGES group. Cohort profile: The Korean Genome and Epidemiology Study (KoGES) consortium. Int J Epidemiol 2017;46:1350.

13. Koo BS, Jeong HJ, Son CN, Kim SH, Kim HJ, Kim GH, et al. Distribution of serum uric acid levels and prevalence of hyper- and hypouricemia in a Korean general population of
172,970. Korean J Intern Med 2021;36(Suppl 1):S264-72.

14. Levey AS, Bosch JP, Lewis JB, Greene T, Rogers N, Roth D. A more accurate method to estimate glomerular filtration rate from serum creatinine: a new prediction equation. Modification of Diet in Renal Disease Study Group. Ann Intern Med 1999;130:461-70.

15. Levey AS, Greene T, Kusek JW, Beck GJ. A simplified equation to predict glomerular filtration rate from serum creatinine. J Am Soc Nephrol 2000;11:155A.

16. Iseki K, Ikemiya $Y$, Inoue $\mathrm{T}$, Iseki $\mathrm{C}$, Kinjo K, Takishita S. Significance of hyperuricemia as a risk factor for developing ESRD in a screened cohort. Am J Kidney Dis 2004;44: 642-50.

17. Obermayr RP, Temml C, Gutjahr G, Knechtelsdorfer M, Oberbauer R, Klauser-Braun R. Elevated uric acid increases the risk for kidney disease. J Am Soc Nephrol 2008;19: 2407-13.

18. Park JT, Kim DK, Chang TI, Kim HW, Chang JH, Park SY, et al. Uric acid is associated with the rate of residual renal function decline in peritoneal dialysis patients. Nephrol Dial Transplant 2009;24:3520-5.

19. Kuo CF, Luo SF, See LC, Ko YS, Chen YM, Hwang JS, et al. Hyperuricaemia and accelerated reduction in renal function. Scand J Rheumatol 2011;40:116-21.

20. Sedaghat S, Hoorn EJ, van Rooij FJ, Hofman A, Franco OH, Witteman JC, et al. Serum uric acid and chronic kidney disease: the role of hypertension. PLoS One 2013;8:e76827.

21. Khosla UM, Zharikov S, Finch JL, Nakagawa T, Roncal C, $\mathrm{Mu} \mathrm{W}$, et al. Hyperuricemia induces endothelial dysfunction. Kidney Int 2005;67:1739-42.

22. Hong Q, Qi K, Feng Z, Huang Z, Cui S, Wang L, et al. Hyperuricemia induces endothelial dysfunction via mitochondrial $\mathrm{Na}^{+} / \mathrm{Ca}^{2+}$ exchanger-mediated mitochondrial calcium overload. Cell Calcium 2012;51:402-10.

23. Esparza Martín N, García Nieto V. Hypouricemia and tubular transport of uric acid. Nefrologia 2011;31:44-50.

24. Suliman ME, Johnson RJ, García-López E, Qureshi AR, Molinaei H, Carrero JJ, et al. J-shaped mortality relationship for uric acid in CKD. Am J Kidney Dis 2006;48:761-71.

25. Uedono H, Tsuda A, Ishimura E, Nakatani S, Kurajoh M, Mori K, et al. U-shaped relationship between serum uric acid levels and intrarenal hemodynamic parameters in healthy subjects. Am J Physiol Renal Physiol 2017;312: F992-7.

26. Hirasaki S, Koide N, Fujita K, Ogawa H, Tsuji T. Two cases of renal hypouricemia with nephrolithiasis. Intern Med 1997;36:201-5.

27. Ohta T, Sakano T, Ogawa T, Kato J, Awaya Y, Kihara H, et al. Exercise-induced acute renal failure with renal hypouricemia: a case report and a review of the literature. Clin Nephrol 2002;58:313-6.

28. Ohta T, Sakano T, Igarashi T, Itami N, Ogawa T. Exerciseinduced acute renal failure associated with renal hypouricaemia: results of a questionnaire-based survey in Japan. Nephrol Dial Transplant 2004;19:1447-53.

29. Nakamura A, Niimi R, Yanagawa Y. Renal hypouricemia in school-aged children: screening of serum uric acid level before physical training. Pediatr Nephrol 2006;21:1898-900.

30. Kim YH, Cho JT. A case of exercise-induced acute renal failure with G774A mutation in SCL22A12 causing renal hypouricemia. J Korean Med Sci 2011;26:1238-40. 
31. Shen H, Feng C, Jin X, Mao J, Fu H, Gu W, et al. Recurrent exercise-induced acute kidney injury by idiopathic renal hypouricemia with a novel mutation in the SLC2A9 gene and literature review. BMC Pediatr 2014;14:73.

32. Shichiri M, Iwamoto H, Marumo F. Diabetic hypouricemia as an indicator of clinical nephropathy. Am J Nephrol 1990;10:115-22.

33. Mumford SL, Dasharathy SS, Pollack AZ, Perkins NJ, Mattison DR, Cole SR, et al. Serum uric acid in relation to endogenous reproductive hormones during the menstrual cycle: findings from the BioCycle study. Hum Reprod 2013; 28:1853-62.

34. Wingrove CS, Walton C, Stevenson JC. The effect of meno- pause on serum uric acid levels in non-obese healthy women. Metabolism 1998;47:435-8..

35. Hsu YH, Pai HC, Chang YM, Liu WH, Hsu CC. Alcohol consumption is inversely associated with stage 3 chronic kidney disease in middle-aged Taiwanese men. BMC Nephrol 2013;14:254.

36. Schaeffner ES, Kurth T, de Jong PE, Glynn RJ, Buring JE, Gaziano JM. Alcohol consumption and the risk of renal dysfunction in apparently healthy men. Arch Intern Med 2005; 165:1048-53.

37. Park M, Lee SM, Yoon HJ. Association between alcohol intake and measures of incident CKD: an analysis of nationwide health screening data. PLoS One 2019;14:e0222123. 